Revista Iberoamericana, Vol. LXXVII, Núm. 234, Enero-Marzo 2011, 225-234

\title{
VISIONES CUBANAS DEL CÓMIC A TRAVÉS DE SUS REVISTAS
}

\author{
POR \\ Ana Merino \\ The University of Iowa
}

Las revistas especializadas en el estudio de los cómics han tenido a lo largo del siglo veinte un papel fundamental para preservar su incipiente memoria y reivindicar espacios culturales autóctonos. Cuba, que tuvo una relación ambigua con el cómic, sorprende sin embargo por su papel pionero en este tipo de publicaciones especializadas dentro del contexto latinoamericano. Hace algunos años llegaron a mi poder los primeros catorce números de la revista C-LINEA que habían aparecido publicados entre 1973 y 1975 en Cuba. Se la podría considerar como una de las publicaciones especializadas más carismáticas del momento, y llevaba como sobrenombre el de Revista Latinoamericana de Estudio de la Historieta. Tuvo como responsable de la edición a Fidel Morales, y como director artístico a Ponce Lima. En su primer número de 1973 explicaban su "razón de ser" conscientes de las dificultades a las que se enfrentaban al defender un medio que se asociaba a los valores ideológicos de lo que definían como la cultura imperialista estadounidense. Pero al margen de esa realidad alienadora y consumista que imponía el capitalismo reivindicaban una cultura de la secuencia gráfica alejada de esos parámetros:

Una realidad: la historieta, el comic, existe como medio de penetración ideológico del imperialismo, y vale porque llega, porque comunica algo con eficiencia. Aunque ese algo sea alienador, mediocre, y reaccionario. Esos "gustos” están arraigados en el pueblo. Hay que declarar que existe una cultura de la secuencia gráfica. (5)

Existía por lo tanto una cultura cubana autóctona del cómic, que trataba de borrar toda influencia imperialista estadounidense, y estaba ligada a otro tipo de compromiso expresivo que maceraba en una nueva tradición creativa dialogante con América Latina y Europa:

Pero, por suerte existe una alternativa. En Cuba, luego de liquidar los últimos vestigios de toda aquella presa foránea y monopolista, tuvieron posibilidad de iniciar una tradición historietística un grupo no pequeño de jóvenes que fueron formándose en los años duros. Hoy ya esos nuevos valores del pincel y la tinta china "cuelan” sus seriales en muchos países de América Latina y en algunos de Europa. (5) 
Parecía que se iban ganando pequeñas batallas ideológicas contra los personajes estereotípicos del comic clásico estadounidense que habían impregnado las culturales locales de los diferentes países. Ahora nuevos personajes autóctonos que reflejaban las inquietudes de las perspectivas izquierdistas estaban encontrando poco a poco su acomodo en periódicos que antes se dejaban llevar por la inercia del contenido impuesto:

En Chile, en Bolivia, Perú, México, Panamá, etc., aún con desventajas, se arraigan personajes y se agregan nuevos nombres, desalojando poco a poco a los hasta hoy intocables “clásicos” yanquis en periódicos de izquierda y en algunos que tienden a proclamarse liberales. (5)

También destacaban los cambios que se estaban sucediendo dentro de la propia cultura estadounidense del cómic debido la efervescente eclosión de la vertiente contracultural del comix underground. Estos comix cuestionaban la realidad social y política de los Estados Unidos a través de historietas de corte subversivo y provocador que había surgido desde dentro y servían para restringir el impacto de los cómics considerados perniciosos e imperialistas:

Y hasta en las propias entrañas de la Criatura aparecen los casi subversivos "ComiX" como parte de la prensa “underground”. Estos nuevos personajes nacen, según confiesan sus autores, para detener la acción perniciosa de los demás muñequitos norteamericanos (tradicionales), con sus valientes soldados matadores de vietnamitas, sus infantiles superhombres neuróticos y toda la gama de publicaciones que sólo sirve para afirmar valores, mitos y comportamientos que apoyan a las estructuras en el poder. (5)

Había en este editorial que definía su "razón de ser” un serio compromiso con el cómic desde la vertiente ideológica que estimulaba y apoyaba su estudio. Además eran conscientes de su talante pionero, y de lo que aquella arriesgada apuesta intelectual conllevaba, ya que el cómic en Cuba se veía con cierta desconfianza al formar parte del instrumental ideológico del enemigo. Pero para ellos era necesario conocer las posibilidades del medio para así adaptarlas a las vertientes ideológicas del socialismo y demostrar la transcendencia de este lenguaje iconográfico:

Tal vez seamos los primeros en lanzar a la circulación una revista comprometida ideológicamente, para el estudio de este importante lenguaje. Pero aún siendo verdad, no nos sentimos solos. Sabemos que existen muchos buenos historietistas por estos lares subdesarrollados. Gente bloqueada en su posibilidad creadora por la monumental maquinaria publicitaria de los aurigas el Norte. Es necesario conocer el medio, aceptarlo y utilizarlo, para comunicar nuestras ideas, las ideas del socialismo. (5)

$\begin{array}{llllll}\text { Revista Iberoamericana, Vol. LXXVII, Núm. 234, } & \text { Enero-Marzo 2011, 225-234 } \\ \text { ISSN 2154-4794 (Electrónico) }\end{array}$ 
Este primer número de C-LINEA ofrecía además selecciones de artículos que reforzaban su postura ideológica. Muchos de esos textos habían sido sacados de otras publicaciones. Por ejemplo el titulado "El comic político un arma cargada de futuro" había sido publicado previamente en 1971 en “Revista Española” y de esa misma publicación, pero de 1972, provenía el que enfrentaba al personaje argentino de Mafalda con el estadounidense Charlie Brown. También en este primer número se recogía un fragmento de la revista OCLAE de mayo de 1972 en el que a través de una entrevista al periodista chileno Hernán Lavin Cerda, que formaba parte del jurado del Premio Casa de las Américas de 1972, sehablaba
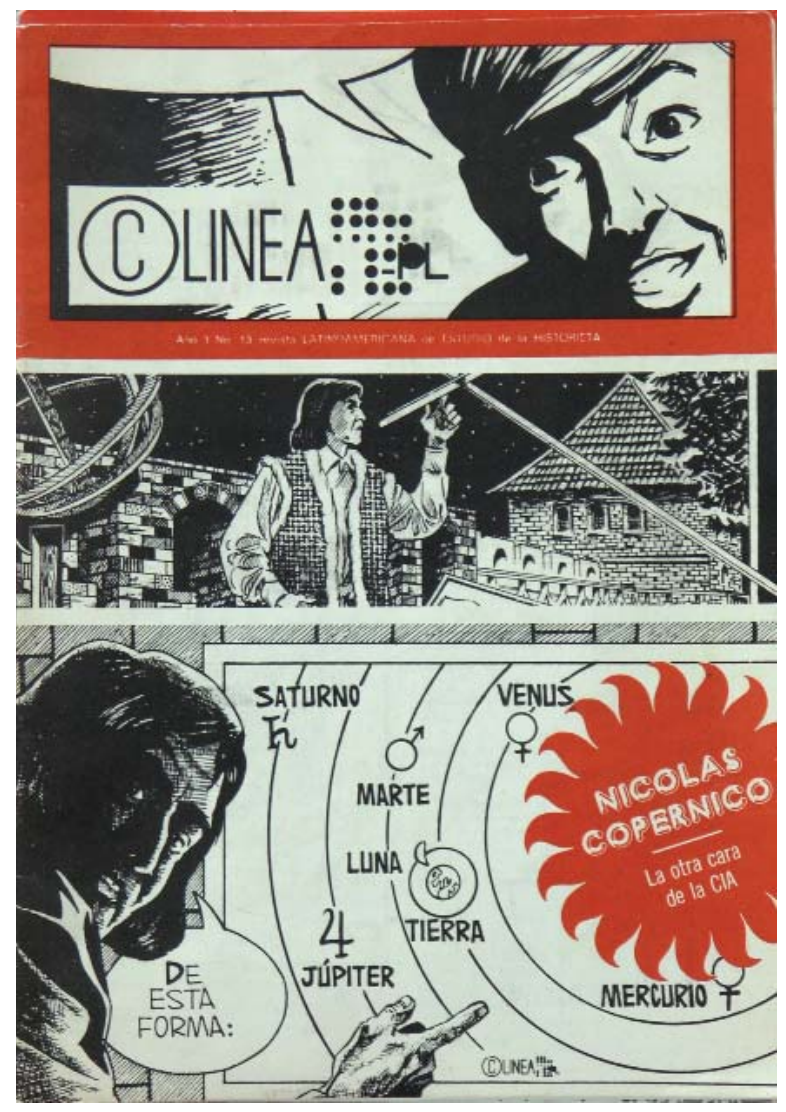
del esfuerzo autóctono

Chileno por producir historietas propias y se aludía a la influencia que había tenido el libro Para leer al Pato Donald de Ariel Dorfman y Armand Mattelart en esa lucha contra el influjo estadounidense:

Se han publicado otras revistas [...] como la revista Cabro Chico, dirigida en lo esencial al mundo infantil, con una intención higienizadora, de sacar a los niños del mundo de la fantasía, del Pato Donald, de Walt Disney. Y en fecha reciente se editó en Chile un libro importante titulado Para leer al Pato Donald en el cual se demuestra cómo en el universo del Pato Donald, en su universo de clase, de explotación, de frialdad, no existe la familia, no existe el trabajo, sólo existe el capital [...] Y este libro pone en evidencia la penetración ideológica que encubre estas series. (9)

$\begin{array}{llllll}\text { ISSN 0034-9631 (Impreso) } & \text { Revista Iberoamericana, Vol. LXXVII, Núm. 234, Enero-Marzo 2011, 225-234 } \\ \text { ISSN 2154-4794 (Electrónico) }\end{array}$ 
La revista Casa de las Américas que funcionaba como espacio de reflexión intelectual canónica del socialismo cubano, dedicaba su número 77 de marzo-abril

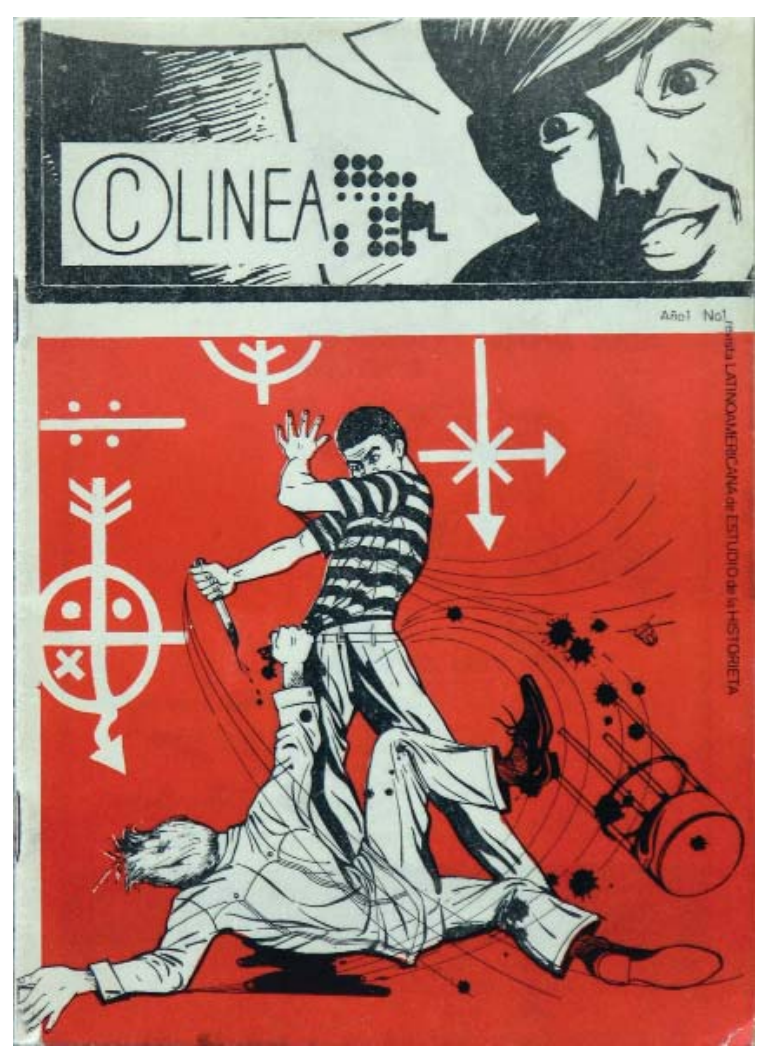
de 1973 al "Imperialismo y los medios masivos de comunicación” y recogía las perspectivas de Dorfman y Mattelart, aderezadas de un rechazo institucional a los cómics. El propio Raúl Castro en su introducción definía como propiciadores -junto con el cine, la radio y la televisión-de "una atmósfera conformista, procapitalista" y “antirrevolucionaria” (4). Los cómics eran vistos como parte del aparato manipulador estadounidense, por eso el nacimiento en aquel momento de una revista como C-LINEA que celebrara y estudiara la historieta tiene mucha relevancia. Es cierto que C-LINEA en sus páginas de arranque no niega que el cómic o la historieta fuera un medio de penetración ideológico del imperialismo, pero también destaca que hay otros países productores de historieta con agendas muy diferentes. Y no sólo eso, sino que además aclara que en los Estados Unidos la aparición de los ComiX underground de talante contracultural está cuestionando los modelos y personajes tradicionales. El equipo editorial de C-LINEA trataba de contrarrestar el peso estético e ideológico del universo del cómic clásico de superhéroes con la reivindicación de tradiciones autóctonas en otras latitudes.

C-LINEA se convirtió en un catalizador de discursos alternativos del cómic con una clara vocación antiimperialista. Como he indicado antes esta publicación va recogiendo fragmentos de artículos de otras revistas, citando sus fuentes, pero celebra también las obras de diferentes autores que comparten sus afinidades ideológicas. Este primer número tomó artículos de "Revista Española”, "Revista OCLAE” o “Madrid” que reflexionaban

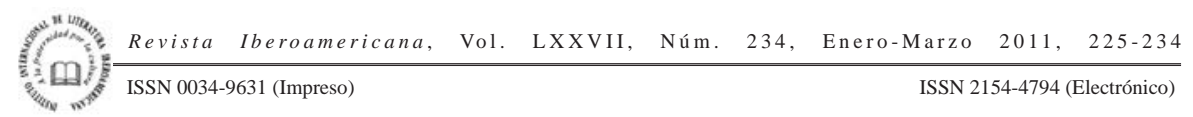


sobre el cómic político o la relación de los intelectuales con el cómic. Superman era visto como un personaje al servicio del Pentágono, pero Cuba creaba sus propios héroes de papel mas humanos para contrarrestar aquella estética de los superpoderes. Este primer número se cerraba con una entrevista a Mario Ponce guionista de "El Endure" una historieta que realizaba con Manuel Serpa y que aludía las históricas tensiones multirraciales en la isla, la posición subalterna del negro y el poder represor del blanco. La historieta narraba un homicidio en plena dictadura de Batista. El protagonista es Julito, un chico negro que mata a un blanco que ha abusado de su hermana.

El segundo número de C-LINEA incluía en el equipo de realización al grupo P-ELE que lo formaba además de Fidel Morales, Newton Estapé, Mario Ponce, Vicente Sánchez, Virgilio Jordi y Héctor Delgado. En su solapa se indica el mes de la publicación, que es el de Junio, además del año 1973. Por otra parte la revista ahora pide a sus lectores que dirijan su correspondencia a Prensa Latina en París. Aunque a partir del número 6 del año 2 (1974) se vuelve a pedirque lacorrespondencia se dirija a la dirección de Prensa Latina en el Vedado, La Habana.

El editor por otra parte a partir del segundo número se curaba en salud afirmando que la revista insertaba artículos para "una mejor comprensión del género" pero que esto no implicaba que se identificasen con lo que expresaban (3). Esa advertencia editorial posibilitaba una mayor diversidad de artículos, aunque la revista se centrase sobre todo en demostrar el potencial historietístico del bloque socialista y la crítica tenaz a los comics generados en el contexto imperialista. Así en un artículo explicaban la proyección de los creadores húngaros que exportaban
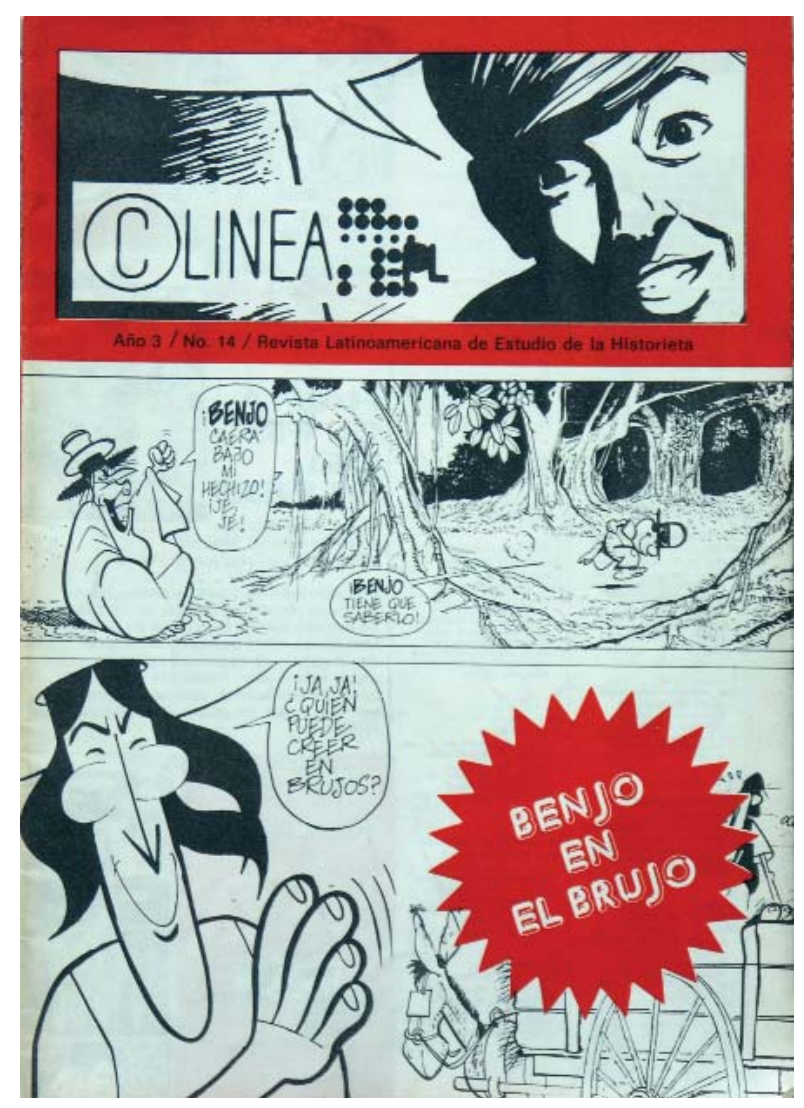

Revista Iberoamericana, Vol. LXXVI, Núm. 234, Enero-Marzo 2011, $225-234$
ISSN 2154-4794 (Electrónico) 
a siete países, o en otro analizaban el peso de los "muñequitos" (otra forma de denominar al cómic o la historieta) como medio de penetración ideológica.

Como la reivindicación de lo autóctono era clave en el discurso de la revista, Fidel Morales ofrecía un artículo dedicado la primera muestra de historieta cubana que había tenido lugar en el Salón de la Solidaridad del hotel Habana Libre. Así explicaba como se habían expuesto los trabajos de mas de treinta historietistas entre los que destacaban "algunas páginas dibujadas antes del triunfo de la Revolución: por Chago de Armas, Virgilio Martínez y René de la Nuez” (5). También estaban presentes los trabajos de Padrón, Hernán H o Lillo. Se

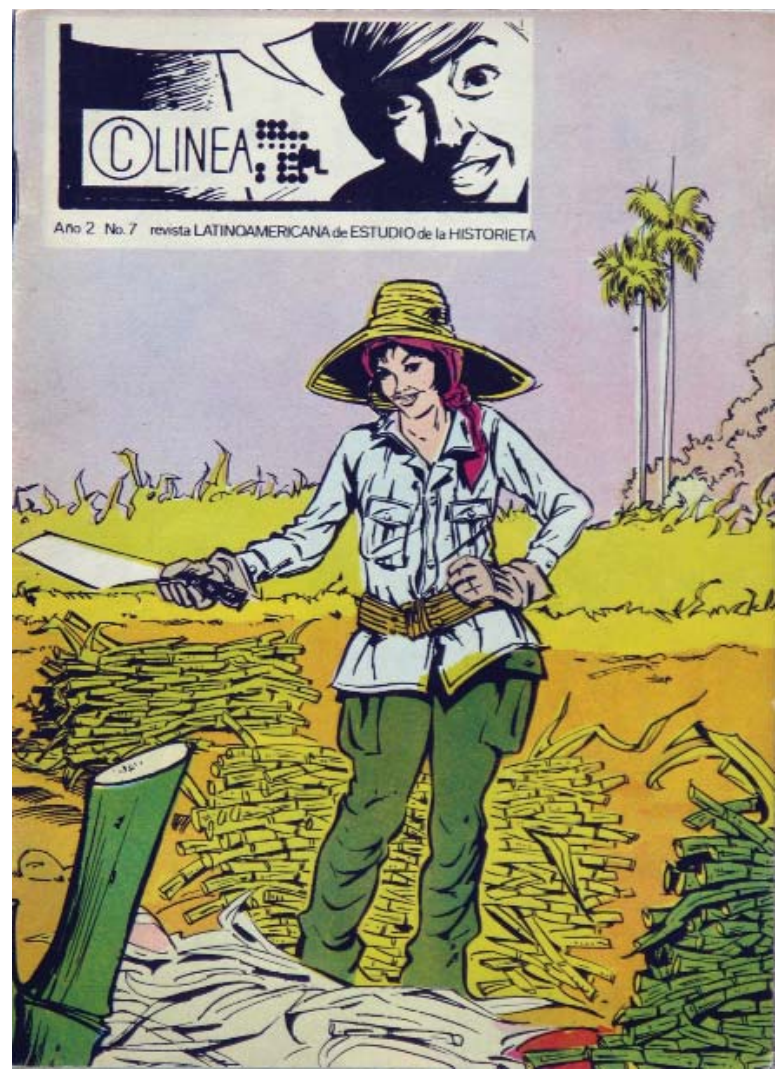
mostraban ademáshistorietas "serias" como las de Túpac Amaru o el general Sandio. Y todo esto se complementaba con un panel central dedicado "a mostrar el serial didáctico-humorístico: 'La vaca Matilda’ de Blanquito” (5). Fidel Morales reflexionaba sobre la influencia estética que habían tenido los cómic clásicos norteamericanos y ahondaba en el esfuerzo que los artistas cubanos tenían que hacer por cambiar la dinámica ideológica de sus propias narrativas gráficas:

Si se trata de escuelas, lo expuesto tendría su génesis en los clásicos malditos de origen yanqui. Aún en Virgilio, Robe, Newton, Lorenzo, Ubaldo y muchos otros, esos orígenes están presentes y mantienen una influencia estructural. En la exposición sólo dos: Luis Vega, con una semiótica novísima, Luis Ruiz, con una gran plasticidad, presentan logros que habría que achacar a otras galaxias. Los demás no salen de los cánones convencionales del cómic tradicional, sin olvidar el contenido, que muchas veces sólo ha sustituido valores. (6)

$\begin{array}{llllll}\text { Revista Iberoamericana, Vol. LXXVII, Núm. 234, Enero-Marzo 2011, 225-234 } & \text { ISSN 2154-4794 (Electrónico) }\end{array}$ 
La pasión por el cómic se mezclaba con la reivindicación de un nuevo cómic vanguardista y revolucionario donde los valores del socialismo cubano macerasen creando nuevas identidades discursivas en el contexto de este arte secuencial:

Hay que incorporarle a la historieta cubana sus propias valoraciones y el resabio de seculares problemas; liquidar el esquema melodramático burgués, reencontrar el lenguaje que la represente y no desmayar hasta alcanzar sumas artísticas que permitan una confrontación. Pero velando porque no se desvirtúe el papel de comunicador de masas [...] es necesario marchar por derroteros genuinamente revolucionarios. (6)

En este segundo número de C-LÍNEA había un artículo que destacaba la importancia del grupo P-ELE. Celebraba su trabajo colectivo y su anhelo por buscar un lenguaje de comunicación popular donde se recogieran, a través de historietas ambientadas en la zafra azucarera, los valores de la juventud revolucionaria. El número se cerraba con una entrevista al dibujante Newton Estape y un fragmento de su historieta "Tupac Amaru”.

El tercer número que apareció en septiembre del 73 se centraba en la historieta de la guerrilla Cubana, ponía en su portada al personaje de Julito 26 que había creado Chago Armada en los tiempos de la revolución. Además recogía una reseña sobre Chago que había aparecido en "Granma” el 3-8 del 73. De nuevo en este número aparecía un extenso artículo de Fidel Morales reflexionando sobre la historieta y su relación con las sociedades en las que se inserta:

La historieta en el marco de la sociedad capitalista y de los países dependientes, no nace como necesidad popular de expresión, sino como producto de consumo. Sólo en los países liberados del dominio económico imperialista pueden desarrollarse dibujantes calificados y, sin presiones editoriales, dedicarse (que es lo importante) al ejercicio pleno de su arte. (7)

El número 4 aparecido en diciembre del 73 tiene en su portada al personaje de Elpidio Valdés que había sido creado por Juan Padrón en 1970 para el semanario "Pionero". Hay también un apartado dedicado a "los buenos narradores" en los que se recoge un artículo sobre Guido Crepax y otro sobre Raymond Poivet, y cierran el número con una historieta de Elpidio Valdés.

En 1974 aparecen ocho ejemplares "del número 5 al número 12 -que dejan de incluir la alusión al mes de publicación en su solapa-. La revista continúa en la misma dinámica de recoger artículos críticos de diversas revistas con los de elaboración propia. En este caso el número cinco incluye una historieta del chileno Alberto Vivanco titulada "Juanita la lista", y cierra la revista con la historieta titulada "Amilcar Cabral” dibujada por Vicente Sánchez y escrita por Fidel Morales. La reivindicación de figuras históricas, como la del héroe guineano, consolida la tendencia realista de un tipo de cómic que quiere contrarrestar las influencias de la fantasía y la ficción científica. Como ya he

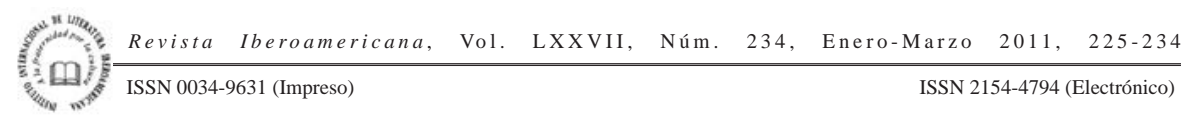


indicado anteriormente en una breve reseña sobre el tema para la revista Leer, todos estos cuadernillos de C-LINEA ofrecieron ejemplos de historietas autóctonas que trataron de asentar una genealogía que no se limitara únicamente a la producción cubana, sino que también abarcase al resto de los países latinoamericanos. El número 6 se cierra con una historieta de corte histórico realista dibujada por Yordi y con guión de Fidel Morales que se centra en el asalto a la fortaleza militar Moncada que tuvo lugar el 26 de julio de 1953. Un dato curioso es que a la historieta se le añade un apéndice con la traducción al francés y al inglés de los textos de las cartelas y los bocadillos. Lo cual denota un esfuerzo por internacionalizar la revista más allá del espacio lingüístico hispánico. A partir de este número el sumario del contenido aparecerá traducido en las tres lenguas.

En su tercer año, el de 1975, la revista cambió su formato de media cuartilla al de cuartilla completa. Con el número 14, dedicado al personaje de Benjo “el Brujo", creado por Pili y Claudio, termina esta pequeña muestra de ejemplares que llegó a mis manos

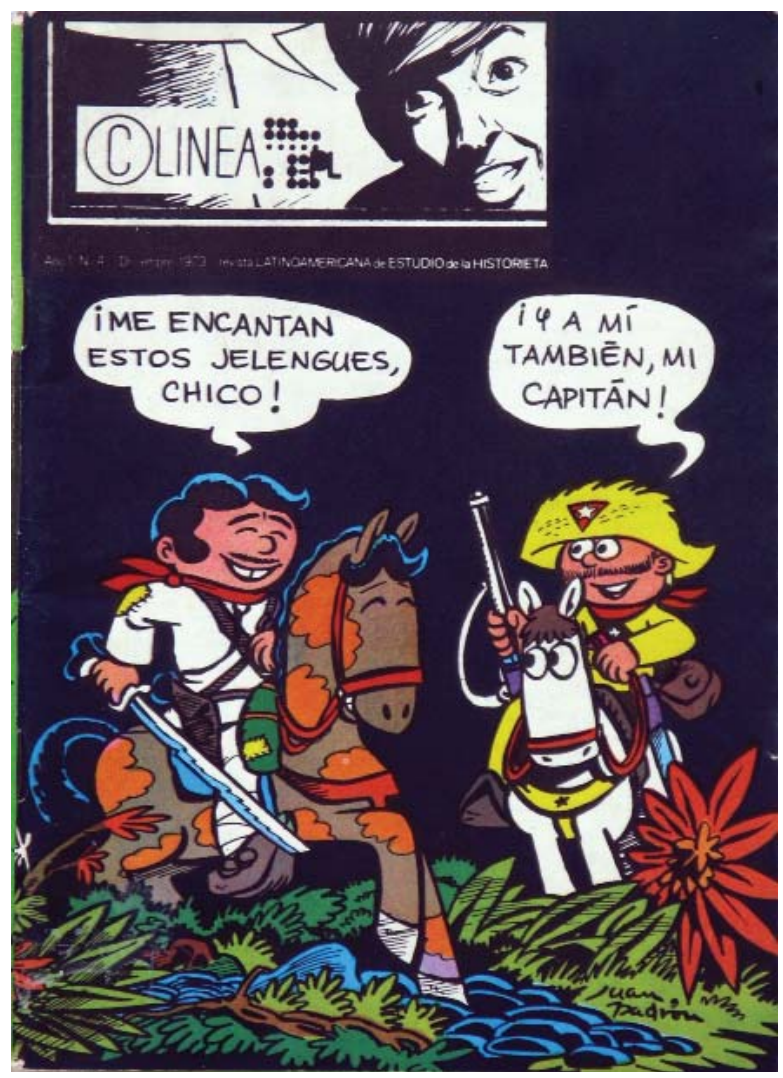
gracias a la generosidad del periodista y editor español Jesús Egido. En mi viaje a Cuba en la primavera de 1999 oí hablar de C-LINEA en numerosas ocasiones, pero no fui capaz de localizar ningún ejemplar. Diez años después en un viaje a Madridme encontrécon este regalo que me ha servido para escribir esta nota, y confirmar una vez más que la aventura académica del estudio de los cómics del siglo $\mathrm{xx}$ en Latinoamérica depende en muchos casos de la generosidad de los coleccionistas que hacen accesibles las publicaciones que fueron saliendo por aquel entonces. Las bibliotecas de la Habana habían perdido la mayor parte del fondo editorial de este tipo de publicaciones, o nunca las llegaron a tener. Si 
Jesús Egido poseía estos 14 ejemplares era porque a lo largo de los setenta Prensa Latina se los había hecho llegar. Egido, con su talante curioso y organizado, los había guardado durante todos estos años en un rincón de su oficina hasta que un día se acordó de mí y de lo mucho que me gustan los cómics.

La revista “C-LINEA” es una pieza clave para entender el significado del cómic en Cuba en la década de los sesenta y poder definir las inquietudes que tuvieron muchos creadores dentro del contexto intelectual de la isla. En ella se perciben claramente las tensiones ideológicas frente a los modelos estadounidenses. Y como esa reacción generó líneas de trabajo donde los héroes manejaban discursos

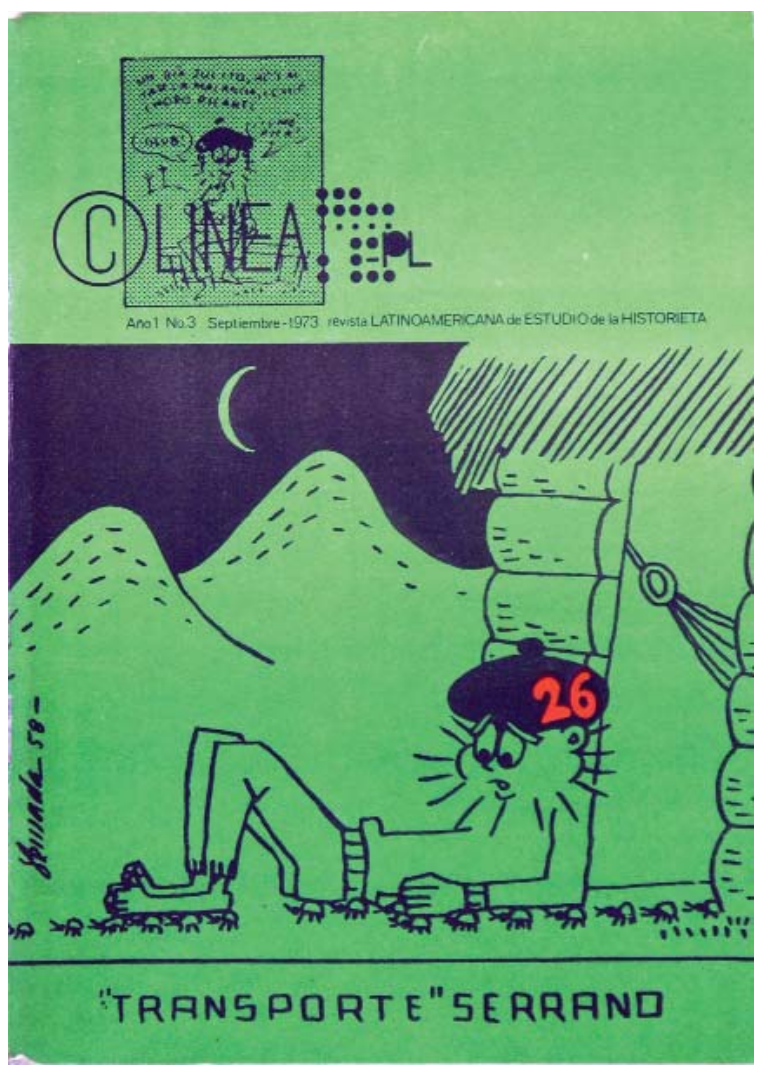
socialistas revolucionarios

que trataban de demostrar que los cómics no eran un monopolio del capitalismo. Años después en Abril del 2001 apareció publicada por la Editorial Pablo de la Torriente la "Revista latinoamericana de estudios sobre la historieta" como parte del Observatorio permanente sobre la historieta latinoamericana. De formato pequeño similar a los primeros números de C-LINEA, en su primeras página explica la falta de información y análisis sobre la producción de historietas en la mayor parte de los países de América Latina exceptuando Argentina, México y Brasil. Se plantea como un espacio abierto de diálogo y pide colaboraciones:

La revista es, por tanto, abierta, y solicita la colaboración de cuantos en América Latina y otros países estén interesados y disponibles a dar su contribución al proyecto con trabajos caracterizados por el máximo rigor científico [...] El rigor metodológico que será adoptado en la valoración y selección de las contribuciones para publicar será

\footnotetext{
Revista Iberoamericana, Vol. LXXVII, Núm. 234, Enero-Marzo 2011, 225-234
ISSN 2154-4794 (Electrónico)
} 
garantizado mediante un comité cinético internacional que trabajará junto a la dirección de la revista. Dicho comité se irá creando y complementando en el tiempo a medida que se establezcan adecuadas relaciones con los estudiosos del género en los países de América Latina. (1-2)

El discurso ideológico con Irma Armas Fonseca de directora, potencia el desarrollo de un espacio de análisis abierto a un diálogo fluido de perspectivas teóricas sobre el medio. Ahora la prioridad es consolidar el universo analítico de los cómics y reivindicar la memoria cultural que los caracteriza en cada uno de los países en los que se producen. Ya no se preocupa tanto de articular planteamientos ideológicos que polaricen a los países productores. La revista además incorpora la experiencia de la página web $<$ http:// www.rlesh.110mb.com/> como vehículo que facilita la diseminación de sus contenidos. La experiencia intelectual cubana en torno al cómic gracias a este tipo de publicaciones encuentra nuevos mecanismos que ayudan a preservar su memoria.

\section{BiBliografíA}

C-LINEA. Revista Latinoamericana de Estudios de la Historieta. Año 1, Número 1 (1973). Talleres Prensa Latina, Vedado, La Habana.

C-LINEA. Revista Latinoamericana de Estudios de la Historieta. Año 1, Número 2. (junio, 1973). Talleres Prensa Latina, Vedado, La Habana.

C-LINEA. Revista Latinoamericana de Estudios de la Historieta. Año 1, Número 3. (septiembre, 1973). Talleres Prensa Latina, Vedado, La Habana.

C-LINEA. Revista Latinoamericana de Estudios de la Historieta. Año 1, Número 4 (diciembre, 1973). Talleres Prensa Latina, Vedado, La Habana.

C-LINEA. Revista Latinoamericana de Estudios de la Historieta. Año 1, Número 3 (septiembre, 1973). Talleres Prensa Latina, Vedado, La Habana.

C-LINEA. Revista Latinoamericana de Estudios de la Historieta. Año 2, Números 5, 6, 7, 8, 9,10, 11, 12. Talleres Prensa Latina, Vedado, La Habana.

C-LINEA. Revista Latinoamericana de Estudios de la Historieta. Año 3, Número 13, 14. Talleres Prensa Latina, Vedado, La Habana.

Merino, Ana. “La Revista 'C-Linea’ y la investigación de los cómics en Cuba”. Leer 26/211 (abril 2010): 98-99.

Revista casa de las Américas. Imperialismo y medios masivos de comunicación. Número 77 (marzo-abril 1973).

Revista latinoamericana de estudios sobre la historieta. Vol.1 (abril, 2001). Editorial Pablo de la Torriente. La Habana, Cuba.

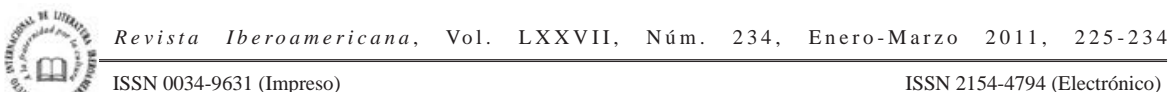

